\title{
Critical appraisal of the role of rituximab in the treatment of patients with previously untreated or treated chronic lymphocytic leukemia (CLL)
}

This article was published in the following Dove Press journal:

Journal of Blood Medicine

18 June 2010

Number of times this article has been viewed

\section{Aref Al-Kali \\ William Wierda \\ Michael Keating \\ Susan O’Brien}

Leukemia Department, UT MD Anderson Cancer Center, Houston, Texas, USA
Correspondence: Susan O'Brien

Leukemia Department, UT MD Anderson

Cancer Center, Houston TX 77030, USA

$\mathrm{Tel}+\mathrm{I} 7137927305$

Fax +I 7135637746

Email sobrien@mdanderson.org

\begin{abstract}
Patients with chronic lymphocytic leukemia (CLL) have benefited from the introduction of targeted therapy for leukemia. Rituximab (a chimeric murine-derived monoclonal antibody that targets CD20 on lymphocytes) was the first monoclonal antibody to affect the natural course of this disease. Several reports have shown modest single-agent activity in patients with CLL. However, the best results come from the combination of this agent with chemotherapy; a significant benefit has been seen with the use of fludarabine, cyclophosphamide, and rituximab (FCR). The addition of rituximab to chemotherapy boosted overall response rates, complete response rates and prolonged progression free survival. Recent data showed an overall survival benefit with FCR. Other combinations including bendamustine and rituximab appear more effective than bendamustine alone, while combining rituximab with other types of agents also appears to improve response rates. This type of relatively nontoxic regimen is being investigated in elderly patients who may not tolerate standard combination chemoimmunotherapies.
\end{abstract}

Keywords: chronic lymphocytic leukemia, rituxan, bioimmunotherapy

\section{Introduction}

Chronic lymphocytic leukemia (CLL) is the most common leukemia in the Western world. It is estimated that 15,490 patients will be diagnosed and 4,390 will die of CLL in 2009 in the USA. ${ }^{1}$ It is considered by the World Health Organization (WHO) to be one of the indolent mature B-cell neoplasms and is classified with small lymphocytic lymphomas. ${ }^{2}$ CLL is diagnosed by the presence of a typical B-cell immunophenotype

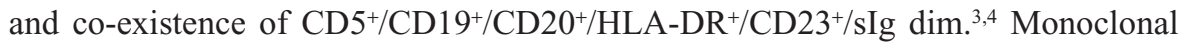
antibodies targeting CD20 have been evaluated in the treatment of CLL due to wide expression of this surface antigen on leukemic cells. CD20 is a calcium channel that interacts with the B-cell immunoglobulin receptor complex (BCR) and is present on both normal and malignant B-cells. ${ }^{5}$ It is important to note that the antigen density of CD20 on CLL cells is significantly less than that seen in lymphoma.

\section{Rituximab}

Rituximab is a chimeric murine-derived monoclonal antibody that consists of a human IgG1-k constant regions and variable regions from the murine monoclonal anti-CD20 antibody IDEC-2B8. It recognizes CD20 and activates complement and promotes C3b deposition in close proximity to cell-bound rituximab. Rituximab exerts its actions via several pathways including antibody-dependent cellular activity (ADCC), complementdependent cytotoxicity (CDC), and through apoptosis via activation of caspase $3 .^{6,7}$ 
Resistance to rituximab in cell lines has been linked to the presence of surface antigens such as CD55 and CD59; which block CDC/ADCC. ${ }^{8,9}$

Maloney et al evaluated rituximab in a phase I study using a single dose of $10-50 \mathrm{mg} / \mathrm{m}^{2}$ in patients with relapsed B-cell non-Hodgkin lymphoma (NHL) and then obtained biopsies two weeks later to confirm binding of the antibody. They showed rapid depletion of B-cells, positive binding to tumor cells, and no dose limiting toxicity. ${ }^{10}$ Another phase I study used rituximab weekly $\times 4$ at doses of 125,275 , and $375 \mathrm{mg} / \mathrm{m}^{2}$ in patients with relapsed lymphoma. ${ }^{11}$ Six of 14 patients (40\%) with low grade lymphoma responded and $375 \mathrm{mg} / \mathrm{m}^{2}$ was selected for phase II studies.

\section{Single-agent rituximab}

McLaughlin et al authored the pivotal phase II study in 1998 using rituximab $375 \mathrm{mg} / \mathrm{m}^{2} \mathrm{IV}$ weekly $\times 4$ in patients with relapsed low grade lymphoma; 48\% responded, the response rate was only $13 \%$ in patients with small lymphocytic lymphoma (SLL). ${ }^{12}$ Several other studies reported similar response rates (Table 1). ${ }^{13-17}$ In an attempt to improve the efficacy of rituximab, 2 trials evaluated higher doses or more frequent administration. Doses of $500 \mathrm{mg} / \mathrm{m}^{2}$ to $2250 \mathrm{mg} / \mathrm{m}^{2}$ IV weekly $\times 4$ were given to 40 patients with CLL yielding an overall response rate (ORR) of $29 \%$ at a dose of $500 \mathrm{mg} / \mathrm{m}^{2}$ and $75 \%$ at a dose of $2250 \mathrm{mg} / \mathrm{m}^{2}$. All responses were partial remission (PR) and time to progression (TTP) was 8 months. ${ }^{18}$ Thrice weekly rituximab at $375 \mathrm{mg} / \mathrm{m}^{2} \times 4$ weeks was evaluated by Ohio State University in 33 patients with SLL/CLL; this produced an ORR of 45\%; one complete remission (CR) was seen. ${ }^{19}$ Rituximab has also been evaluated as frontline therapy for CLL. Hainsworth et al assessed rituximab $375 \mathrm{mg} / \mathrm{m}^{2}$ IV weekly $\times 4$ in untreated patients with CLL with maintenance rituximab for patients who had objective response or stable

Table I Rituximab single agent trials

\begin{tabular}{|c|c|c|c|c|c|}
\hline Ref & Prior Rx & $\mathbf{N}$ & Doses (W) & ORR\% & PFS/TTP \\
\hline McLaughlin ${ }^{12}$ & $Y$ & 30 & 4 & 13 & ND \\
\hline Nguyen $^{13}$ & $Y$ & 12 & 4 & 0 & ND \\
\hline Winkler ${ }^{14}$ & $Y$ & 9 & 4 & II & ND \\
\hline Ladetto $^{15}$ & $Y$ & 7 & 4 & 0 & ND \\
\hline Huhn $^{16}$ & $Y$ & 28 & 4 & 25 & TTP I6 w \\
\hline Itala ${ }^{17}$ & $Y$ & 24 & 4 & 35 & TTP I $2.5 \mathrm{w}$ \\
\hline O’Brien $^{18}$ & $Y$ & 40 & $4(500-2250)$ & 36 & TTP 8 m \\
\hline Byrd $^{19}$ & $Y$ & 33 & $4($ thrice/w) & 45 & PFS 9 m \\
\hline Hainsworth ${ }^{20}$ & $N$ & 44 & 4 & 51 & $18.6 \mathrm{~m}$ \\
\hline Thomas ${ }^{21, *}$ & $\mathrm{~N}$ & 21 & 8 & 21 & ND \\
\hline
\end{tabular}

Note: *No standard indication for therapy, high risk features

Abbreviations: Ref, reference; Prior Rx, prior therapy; N, number of patients; ORR, overall response rate; PFS, progression free survival; TTP, time to progression; ND, not given; $W$, weekly. disease. This yielded a 9\% CR and a 58\% ORR; progression free survival (PFS) was 18.6 months. ${ }^{20}$ Thomas et al gave rituximab $375 \mathrm{mg} / \mathrm{m}^{2}$ IV weekly $\times 8$ weeks to patients with previously untreated CLL with high beta-2 microglobulin but no standard indication for treatment; this provided an ORR of $90 \%$ and a CR rate of $19 \% .^{21}$

\section{Rituximab and chemotherapy}

The Cancer and Leukemia Group B (CALGB) 9712 randomized 104 chemonaive patients to concurrent vs sequential fludarabine and rituximab (FR) therapy. Fludarabine was given at $25 \mathrm{mg} / \mathrm{m}^{2}$ IV days $1-5$ every 28 days for 6 cycles while rituximab was given at $375 \mathrm{mg} / \mathrm{m}^{2} \mathrm{IV}$ on day 1 of each cycle (an additional dose on cycle one day 4 was given to ensure adequate saturation of CD20 binding sites). ${ }^{22}$ Sequential rituximab $375 \mathrm{mg} / \mathrm{m}^{2}$ weekly $\times 4$ was given 2 months after the end of fludarabine or FR if patients had at least stable disease or better per National Cancer Institute (NCI) criteria. Ninety percent ORR including $47 \% \mathrm{CR}$ was achieved in the concurrent arm compared to $77 \%$ ORR and $28 \% \mathrm{CR}$ in the sequential arm. However, in a recent update with a long-term follow up, there was no difference in PFS or overall survival (OS) between concurrent vs sequential arms; with an estimated $17 \%$ of responders still in remission 8 years later. ${ }^{23}$ The Europeans showed similar results in a multi-center phase II study using FR. ${ }^{24}$ A retrospective comparison between CALGB 9712 and 9011 (single-agent fludarabine [F]) showed a superior ORR with FR vs F (84\% vs 63\%), as well as a superior 2-year PFS $(67 \%$ vs $45 \%)$ and 2 -year OS (93\% vs $81 \%){ }^{25}$

MD Anderson Cancer Center (MDACC) evaluated fludarabine, cyclophosphamide and rituximab in both treated and untreated patients (Table 2). Fludarabine $25 \mathrm{mg} / \mathrm{m}^{2}$, cyclophosphamide $250 \mathrm{mg} / \mathrm{m}^{2}$ on days 2-4 of cycle one and on days $1-3$ of cycles $2-6$, and rituximab $375 \mathrm{mg} / \mathrm{m}^{2}$ on day 1 of cycle one and $500 \mathrm{mg} / \mathrm{m}^{2}$ on day 1 of cycles $2-6$ (fludarabine, cyclophosphamide, and rituximab [FCR]) were given every 28 days for a total of 6 cycles to 177 patients with relapsed CLL. ${ }^{26}$ The ORR was $73 \%$ with $25 \%$ CR, $16 \%$ nodular PR and $32 \%$ PR. Thirty-two percent of complete responders achieved molecular remission in the bone marrow. FCR was given to 300 patients with previously untreated CLL producing a 94\% ORR, including a $72 \%$ CR rate, nodular partial remission in $10 \%$, and partial remission due to cytopenia and residual disease in $7 \%$ and $6 \%$ respectively. ${ }^{27,28}$ Median time to progression was 80 months with a 6 -year OS of $77 \%$, and responses predicted longer survival.

Lamanna et al used another purine analogue, pentostatin, in patients with relapsed CLL. Pentostatin $4 \mathrm{mg} / \mathrm{m}^{2}$, 
Table 2 Nucleoside analogues/rituximab trials

\begin{tabular}{|c|c|c|c|c|c|c|c|}
\hline Ref & Regimen & Rituxan & Prior Rx & Phase & $\mathbf{N}$ & ORR\% (CR\%) & PFS/TTP \\
\hline Keating ${ }^{28}$ & FCR & $500 q 4 w$ & No & II & 300 & $95(72)$ & TTP $80 \mathrm{~m}$ \\
\hline $\mathrm{Kay}^{30}$ & PCR & 375 q 3w & No & II & 64 & $91(4 I)$ & PFS $32.6 \mathrm{~m}$ \\
\hline \multirow[t]{2}{*}{ Hallek $^{31}$} & FCR & 500 q $3 w$ & No & III & 817 & $95(52)$ & PFS 43 m \\
\hline & FC & & & & & $88(27)$ & PFS 32 m \\
\hline \multirow[t]{2}{*}{ Byrd ${ }^{22}$} & FR con & $375 q 4 w$ & No & ॥ & 104 & $90(47)$ & NR \\
\hline & FR seq & & & & & $77(28)$ & NR \\
\hline \multirow[t]{2}{*}{ Schulz ${ }^{24}$} & $\mathrm{FR}$ & $375 q 4 w$ & No & II & 20 & $85(25)$ & ND \\
\hline & & (cycle 3) & Yes & & 11 & $91(45)$ & \\
\hline Wierda $^{26}$ & FCR & 500 q $3 w$ & Yes & II & 177 & $73(25)$ & PFS 28 m \\
\hline Lamanna $^{29}$ & PCR & 375 q 3w & Yes & ॥ & 46 & $75(25)$ & TTP 25 m \\
\hline \multirow[t]{2}{*}{ Robak $^{32}$} & FCR & 500 q 3w & Yes & III & 552 & $70(24)$ & PFS $30.6 \mathrm{~m}$ \\
\hline & FC & & & & & $50(13)$ & PFS $20.6 \mathrm{~m}$ \\
\hline
\end{tabular}

Abbreviations: Ref, reference; Prior Rx, prior therapy; N, number of patients; ORR, overall response rate; CR, complete remission; PFS, progression free survival; TTP, time to progression; ND, not given; W, weekly; M, month; Con, concurrent; Seq, sequential; NR, not reached.

cyclophosphamide $600 \mathrm{mg} / \mathrm{m}^{2}$ (starting cycle one) and rituximab $375 \mathrm{mg} / \mathrm{m}^{2}$ (starting cycle two) (PCR) were given IV on day 1 every 3 weeks $\times 6$ to 46 patients with relapsed CLL yielding an ORR of $75 \%$ including $25 \% \mathrm{CR} .{ }^{29}$ This regimen was assessed in the front-line setting by Kay et al in 64 previously untreated patients with CLL who received the combination of pentostatin $2 \mathrm{mg} / \mathrm{m}^{2}$, cyclophosphamide $600 \mathrm{mg} / \mathrm{m}^{2}$ and rituximab $375 \mathrm{mg} / \mathrm{m}^{2}$ IV on day 1 every 3 weeks $\times 6$ cycles. ${ }^{30}$ Responses occurred in $91 \%$ including $41 \%$ CR, $22 \%$ nodular PR, and $28 \%$ PR. This regimen was equally effective in young versus older patients and in those with del 11q22; 0/3 patients with $17 \mathrm{p}$ del reached CR.

Two phase III studies evaluated the comparison of fludarabine and cyclophosphamide (FC) to FCR in a randomized trial. ${ }^{31,32}$ The German CLL Study Group (GCLLSG8) compared FCR to FC in 817 previously untreated patients. ${ }^{31}$ Patients were randomized to receive FC (fludarabine $25 \mathrm{mg} / \mathrm{m}^{2} \mathrm{IV}$, and cyclophosphamide $250 \mathrm{mg} / \mathrm{m}^{2} \mathrm{IV}$ days $1-3$ ) or FCR (rituximab $375 \mathrm{mg} / \mathrm{m}^{2}$ IV day 0 in cycle 1 and $500 \mathrm{mg} / \mathrm{m}^{2}$ day 1 of subsequent cycles) every 28 days $\times 6$. ORR was $95 \%$ vs $88 \%$, CR rate $52 \%$ vs $27 \%$ for FCR vs FC respectively. There was improved PFS $(P<0.0001$ vs 0.18$)$. Recently Hallek et al updated their results and showed an OS benefit at 37 months for FCR (84\%) vs FC (79\%) $(P=0.01)$; only patients in Binet stages A and B had a superior OS after FCR therapy ${ }^{33}$ In the REACH study, 552 relapsed patients were randomized to FC vs FCR every 28 days for 6 cycles resulting in a 10-month gain in PFS with FCR. ${ }^{32}$

MDACC added alemtuzumab to the FCR combination in patients with heavily pretreated CLL. ${ }^{34}$ Alemtuzumab $30 \mathrm{mg}$ IV was given on days $1,3,5$, rituximab $375-500 \mathrm{mg} / \mathrm{m}^{2}$ IV day 2 , fludarabine $25 \mathrm{mg} / \mathrm{m}^{2}$ IV days $3-5$, and cyclophosphamide $250 \mathrm{mg} / \mathrm{m}^{2}$ days $3-5$ every 28 days for 6 cycles. Of the 74 patients who completed treatment, $24 \%$ achieved CR, $2.7 \%$ nodular PR, and $37.8 \%$ PR (ORR 65\%). In patients with $17 \mathrm{p}$ del, $44 \%$ responded to cyclophosphamide, fludarabine, alemtuzumab, and rituximab (CFAR), while $19 \%$ of patients treated previously with FCR achieved CR on this regimen. Median survival for all patients was 19 months but more than 35 months for patients achieving CR. This regimen was given by the same group to patients with previously untreated CLL with high risk features (beta- 2 microglobulin $>4$ ) in a phase II study ${ }^{35}$ The initial report on the first 21 patients showed $71 \%$ CR, $5 \%$ nodular PR, PR in $19 \%$. This has been recently updated with no significant change in response rates. ${ }^{36}$ Therefore, it seems that CFAR does not provide better results than FCR as front-line therapy in these high risk patients.

Rituximab was also investigated in combination with bendamustine, a novel alkylating agent which contains a benzimidazole ring and is only partially cross-resistant with other alkylating agents in vitro. Eighty-one patients with relapsed CLL were treated in a phase II multi-center study using bendamustine $70 \mathrm{mg} / \mathrm{m}^{2} \mathrm{IV}$ on days $1-2$ combined with rituximab $375 \mathrm{mg} / \mathrm{m}^{2}$ for cycle one and $500 \mathrm{mg} / \mathrm{m}^{2}$ for cycles 2-6 every 28 days. The ORR was $77 \%$ including $14.5 \%$ CR and $62.9 \%$ PR. ${ }^{37}$ Among the genetics subgroups, ORR was $92.3 \%$ in $11 \mathrm{q}^{-}, 100 \%$ in $12^{+}$and $44.4 \%$ in patients with $17 \mathrm{p}$ del. Bendamustine combined with rituximab (BR) proved to be effective in 117 previously untreated patients with CLL yielding an ORR of $90.9 \%$ (including $32.7 \% \mathrm{CR}$ ). ${ }^{38}$

In summary, FCR appear to be the most effective frontline regimen in CLL based on both single institutional and phase III randomized trial data. The MDACC data indicated a CR rate of $72 \%$ and an ORR of $95 \%$. The German randomized trial (of FCR vs FC) also produced a 95\% ORR in the FCR arm. The CR rate dropped to $44 \%-50 \%$ (including 
uncertain CR), not surprising when single institutional data are reproduced in a large multicenter randomized trial. However, this is still the highest CR rate reported in patients with CLL. However some investigators have questioned whether, given the marked synergy seen when rituximab is added to chemotherapy, the alkylating agent is necessary. In other words would FR be as effective as FCR? The PFS with FR appears to be inferior to that reported with FCR. However, this question will be more definitively answered in the current Intergroup trial comparing FCR to FR with or without lenalidomide maintenance (NCT00602459). While the CR rates with $\mathrm{BR}$, in a smaller study, were inferior to those seen with FCR, the Germans are conducting a randomized study in frontline CLL of BR vs FCR (GCLLSG10, NCT 00769522). PCR also appeared inferior to FCR; of interest is that FCR is clearly less well tolerated in patients over the age of 70 whereas PCR was as safe and effective in elderly patients.

\section{Rituximab and non-chemotherapy agents}

Alemtuzumab is a humanized monoclonal antibody that targets the CD52 antigen. CD52 is a $21-28 \mathrm{kD}$ cell surface glycopeptide expressed on virtually all human lymphocytes, monocytes, macrophages, a small subset of granulocytes, but not erythrocytes, platelets or bone marrow stem cells. It has been FDA approved in both previously untreated and fludarabine refractory patients with CLL. ${ }^{39,40}$ Rituximab has been combined with alemtuzumab in several studies. Faderl et al gave rituximab $375 \mathrm{mg} / \mathrm{m}^{2}$ weekly $\times 4$ with alemtuzumab using a loading-dose schedule of $3 \mathrm{mg}, 10 \mathrm{mg}$, and $30 \mathrm{mg}$ on 3 consecutive days during week 1 and $30 \mathrm{mg}$ on day 3 , 5 of weeks 2-4 with a repeat course depending on response and toxicity. ${ }^{41}$ Twenty of $32(63 \%)$ patients with relapsed CLL achieved response, including 6\% CR. Median TTP was 6 months and median OS was 11 months; 15\% developed symptomatic CMV antigenemia requiring therapy. Mayo Clinic assessed this combination in 30 previously untreated patients with high risk features (del 17p13, del 11q22) and lacking a standard indication for therapy (early therapy) giving alemtuzumab $30 \mathrm{mg}$ weekly $\times 4$ and rituximab $375 \mathrm{mg}$ weekly $\times 4$; this yielded an ORR of $90 \%$ including $37 \% \mathrm{CR}^{42}$

Lenalidomide is an immunomodulatory drug that is a more potent analog of thalidomide and has shown activity in relapsed patients with CLL, including activity in patients with high-risk cytogenetics. ${ }^{43-45}$ Ferrajoli et al recently added rituximab $375 \mathrm{mg} / \mathrm{m}^{2}$ weekly $\times 4$ then every 4 weeks on cycles $3-12$ of lenalidomide $10 \mathrm{mg}$ starting day 9 on cycle one and then daily every 28 days for 12 cycles. ${ }^{46}$ After 6 cycles of therapy 25 of 37 patients achieved response (68\%) including 6 patients with nodular PR, 19 PR, 6 SD; 6 patients failed to respond. Patients with poor cytogenetics features did equally well. This compares favorably to single agent lenalidomide with superior ORRs and less tumor flare reaction. $^{44}$

Rituximab has also been combined with high dose methylprednisolone. Glucocorticoids kill lymphoid cells by a p53 independent mechanism and appear to be active in patients with $17 \mathrm{p}$ deletions. ${ }^{47}$ They also reduce bulky lymphadenopathy and cause less myelosuppression than chemotherapy. Bowen et al reported data from a retrospective study wherein 37 previously treated patients with CLL were given $1 \mathrm{~g} / \mathrm{m}^{2}$ of methylprednisolone daily $\times 5$ and rituximab $375 \mathrm{mg} / \mathrm{m}^{2}$ weekly $\times 4$ with repeat of each cycle up to three. ${ }^{48}$ Seventy-eight percent had an objective response, including 5 of 9 patients with del 17p; however, 29\% developed infectious complications before completing one month of therapy. Several other studies are summarized in Table 3. James et al tested this combination in 28 previously untreated patients using methylprednisolone $1 \mathrm{~g} / \mathrm{m}^{2}$ daily $\times 3$ every 28 days with weekly rituximab $\left(375 \mathrm{mg} / \mathrm{m}^{2} \times 12\right.$ or $750 \mathrm{mg} / \mathrm{m}^{2}$ weekly $\times 7) .{ }^{49}$ The ORR was $96 \%$ including $32 \%$ CR with better response if patients had less prominent splenomegaly and lower beta- 2 microglobulin. This combination is proven to be effective but at the cost of a significant infection rate.

Finally, rituximab was evaluated in combination with human granulocyte macrophage colony stimulating factor (GM CSF); the rationale was the increased surface expression of CD20 seen on some CLL cells with the use of GM CSF in vitro. ${ }^{50}$ Ferrajoli et al gave GM CSF $250 \mu \mathrm{g}$ SC thrice weekly $\times 8$ and rituximab $375 \mathrm{mg} / \mathrm{m}^{2}$ weekly $\times 4$ to 118 patients with CLL ( 3 different groups; elderly previously untreated, high risk with elevated beta- 2 microglobulin and no standard indication for therapy, relapsed patients) achieving 65\% ORR including 9\% CR with minimal side effects including mild GM CSF injection site erythema. These results compare favorably to historical control data using rituximab alone. ${ }^{51}$

\section{Special conditions Complications}

It is known that some patients will experience fever, chills, nausea, vomiting, hypotension and dyspnea predominantly with their first infusion of rituximab. This is known as 'cytokine release syndrome' and is associated with more 
Table 3 Rituximab trials using non-chemotherapy agents

\begin{tabular}{|c|c|c|c|c|c|c|}
\hline Ref & Regimen & Dose & Prior Rx & $\mathbf{N}$ & ORR\% (CR\%) & PFS/TTP \\
\hline \multirow[t]{2}{*}{ Faderl $^{41}$} & Rituximab & $q w \times 4$ & Yes & 32 & $63(6)$ & TTP $6 \mathrm{~m}$ \\
\hline & Alemtuzumab & $302 / w \times 4$ & & & & \\
\hline \multirow[t]{2}{*}{ Nabhan ${ }^{58}$} & Rituximab & $\mathrm{qw} \times 4$ & Yes & 11 & $9(0)$ & ND \\
\hline & Alemtuzumab & $3,10,303 / w \times 4$ & & & & \\
\hline \multirow[t]{2}{*}{ Zent ${ }^{42}$} & Rituximab & $q w \times 4$ & No & 30 & $90(37)$ & TTP $12.5 \mathrm{~m}$ \\
\hline & Alemtuzumab & $303 / w \times 4$ & & & & \\
\hline \multirow[t]{2}{*}{ Frankfurt ${ }^{59}$} & Rituximab & $\mathrm{qw} \times 8$ & No & 20 & $90(75)$ & NR \\
\hline & Alemtuzumab & $303 / w \times 17$ & & & & \\
\hline \multirow[t]{2}{*}{ Ferrajoli ${ }^{46}$} & Rituximab & $\mathrm{qw} \times 4$ then $\mathrm{qm} \times 10$ & Yes & 37 & $68(0)$ & ND \\
\hline & Lenalidomide & $10 \mathrm{mg} \mathrm{qd} \times 12 \mathrm{~m}$ & & & & \\
\hline \multirow[t]{2}{*}{ Bowen ${ }^{48}$} & Rituximab & $q w \times 4$ & Yes & 37 & $78(22)$ & PFS $12 \mathrm{~m}$ \\
\hline & Methylprednisolone & I gm qd $\times 5$ & & & & \\
\hline \multirow[t]{2}{*}{ Dungearwalla $^{60}$} & Rituximab & $q w \times 6$ & Yes & 14 & $93(14)$ & PFS 7 m \\
\hline & Methylprednisolone & I gm qd $\times 5$ & & & & \\
\hline \multirow[t]{2}{*}{ Castro $^{61}$} & Rituximab & $q w \times 4$ & Yes & 14 & $93(36)$ & TTP I5 m \\
\hline & Methylprednisolone & I gm qd $\times 5$ & & & & \\
\hline \multirow[t]{2}{*}{ James $^{49}$} & Rituximab & $375 q w \times 12$ or $750 q w \times 9$ & No & 28 & $96(32)$ & NR \\
\hline & Methylprednisolone & I gm qd $\times 3$ & & & & \\
\hline
\end{tabular}

Abbreviations: Ref, reference; Prior Rx, prior therapy; N, number of patients; ORR, overall response rate; CR, complete remission; PFS, progression free survival; TTP, time to progression; ND, not given; NR, not reached; qw, weekly; qm, monthly; qd, daily.

intense cellular expressions of CD20. Standard premedication with acetaminophen and diphenhydramine is warranted; many people also use steroids, at least before the first dose of rituximab. Thus, the initial infusion of rituximab is usually started slowly with a gradual escalation of the rate. Tumor lysis syndrome has been described with rituximab. Most investigators use allopurinol as well as hydration in patients with high volume disease. Progressive multifocal leukoencephalopathy (PML) is a demyelinating disorder of the brain caused by the reactivation of latent JC polyoma virus. Rituximab has been linked to PML in several diseases (especially SLE) and has been found to be associated with malignancy in 52/57 reported cases; $24.6 \%$ were CLL. ${ }^{52}$ Those patients usually also received chemotherapy agents and seven patients had had prior hematopoietic stem cell transplant. The median time to diagnosis was 5.5 months from the last dose of rituximab and the median number of rituximab doses was 6 . The case-fatality rate was $90 \%$. Another viral reactivation concern is with patients who have had HBV infection. Several reports have documented HBV reactivation with the use of rituximab in patients with NHL and CLL, even with negative HBs Ag. ${ }^{53,54}$

\section{Elderly}

Most published trials of CLL have reported a median age of less than 70, which does not reflect the general population. Data with FCR suggest that patients $>70$ years old are less likely to complete six cycles, less likely to achieve CR, and tend to have more complications. ${ }^{28}$ Kay et al reported a subanalysis of previously untreated patients older than 70 years receiving PCR. ${ }^{55}$ Elderly patients had more delayed cycles ( $28 \%$ vs $7 \%$ ), but there was no significant difference in the total number of cycles given, need for dose reductions, grade 3-4 hematologic, infectious, or other toxicities. In addition there was no significant difference in ORR, CR or even PFS between both younger and older patients.

\section{Maintenance}

Rituximab maintenance has been shown to prolong PFS in patients with NHL. Del Poeta et al gave FR (F $25 \mathrm{mg} / \mathrm{m}^{2}$ daily $\times 5$, every 28 days $\times 6$, and then $\mathrm{R} 375 \mathrm{mg} / \mathrm{m}^{2}$ weekly $\times 4$ ) to 75 previously untreated CLL patients; responders with positive minimal residual disease were given four monthly cycles of rituximab $375 \mathrm{mg} / \mathrm{m}^{2}$ followed by 12 monthly low dose $\left(150 \mathrm{mg} / \mathrm{m}^{2}\right)$ rituximab maintenance. ${ }^{56}$ Twenty-eight patients who received maintenance therapy had longer response duration ( $85 \%$ vs $32 \%$ at 5 years; $P=0.001)$ compared to 18 patients who did not. However; no explanation was given for why the observation group did not receive maintenance, which makes the comparison specious. Foon et al introduced the FCR-Lite regimen with dose reduction of fludarabine and cyclophosphamide, rituximab twice each cycle, and rituximab $500 \mathrm{mg} / \mathrm{m}^{2}$ as maintenance every 3 months until relapse. Rituxan $375 \mathrm{mg} / \mathrm{m}^{2}$ was given on day 1 of cycle 1 then $500 \mathrm{mg}$ on day 1 of cycle $2-6$ and day 14 of cycle $1-6$. Fludarabine $20 \mathrm{mg} / \mathrm{m}^{2}$ and cyclophosphamide $150 \mathrm{mg} / \mathrm{m}^{2}$ were given for 3 days with each cycle. Fifty previously untreated CLL patients achieved 100\% ORR (including 79\% CR) with a 
median duration of complete response of $22.3+$ months and no relapse yet seen in complete responders. ${ }^{57}$ Grade 3-4 neutropenia was noted in $13 \%$ of the cycles which compares favorably to historical data using standard FCR. Further evaluation of this regimen is warranted. There are, as yet, no data from randomized trials of maintenance rituximab in CLL to establish the benefit of this approach.

\section{Conclusion}

In conclusion, rituximab has improved the management of CLL and has become a critical agent in most combination regimens. It increases $\mathrm{CR}$ and ORRs, and prolongs PFS. FCR appears to be the best front-line regimen with a survival benefit seen over chemotherapy alone. Non-chemotherapybased combinations with rituximab may offer safe and effective options for patients who cannot tolerate chemoimmunotherapy. Consolidation and maintenance therapies remain interesting areas of research but randomized trials are needed.

\section{Disclosures}

The authors report no conflicts of interest in this work.

\section{References}

1. SEER Cancer Statistics Review, 1975-2006, National Cancer Institute. Bethesda, MD. 2009. http://seer.cancer.gov/csr/1975_2006/.

2. Jaffe ES, Harris NL, Stein H, Isaacson PG. Classification of lymphoid neoplasms: the microscope as a tool for disease discovery. Blood. 2008;112(12):4384-4399.

3. Cheson BD, Bennett JM, Grever M, et al. National Cancer Institutesponsored Working Group guidelines for chronic lymphocytic leukemia: revised guidelines for diagnosis and treatment. Blood. 1996; 87(12):4990-4997.

4. Hallek M, Cheson BD, Catovsky D, et al. Guidelines for the diagnosis and treatment of chronic lymphocytic leukemia: a report from the International Workshop on Chronic Lymphocytic Leukemia updating the National Cancer Institute-Working Group 1996 guidelines. Blood. 2008;111(12):5446-5456.

5. Reff ME, Carner K, Chambers KS, et al. Depletion of B cells in vivo by a chimeric mouse human monoclonal antibody to CD20. Blood. 1994;83(2):435-445.

6. Byrd JC, Kitada S, Flinn IW, et al. The mechanism of tumor cell clearance by rituximab in vivo in patients with B-cell chronic lymphocytic leukemia: evidence of caspase activation and apoptosis induction. Blood. 2002;99(3):1038-1043.

7. Pedersen IM, Buhl AM, Klausen P, Geisler CH, Jurlander J. The chimeric anti-CD20 antibody rituximab induces apoptosis in B-cell chronic lymphocytic leukemia cells through a p38 mitogen activated protein-kinase-dependent mechanism. Blood. 2002;99(4): 1314-1319.

8. Treon SP, Mitsiades C, Mitsiades N, et al. Tumor cell expression of CD59 is associated with resistance to CD20 serotherapy in patients with B-cell malignancies. J Immunother. 2001;24(3):263-271.

9. Golay J, Lazzari M, Facchinetti V, et al. CD20 levels determine the in vitro susceptibility to rituximab and complement of B-cell chronic lymphocytic leukemia: further regulation by CD55 and CD59. Blood. 20011;98(12):3383-3389.
10. Maloney DG, Liles TM, Czerwinski DK, et al. Phase I clinical trial using escalating single-dose infusion of chimeric anti-CD20 monoclonal antibody (IDEC-C2B8) in patients with recurrent B-cell lymphoma. Blood. 1994;84(8):2457-2466.

11. Maloney DG, Grillo-Lopez AJ, Bodkin DJ, et al. IDEC-C2B8: results of a phase I multiple-dose trial in patients with relapsed non-Hodgkin's lymphoma. J Clin Oncol. 1997;15(10):3266-3274.

12. McLaughlin P, Grillo-Lopez AJ, Link BK, et al. Rituximab chimeric antiCD20 monoclonal antibody therapy for relapsed indolent lymphoma: half of patients respond to a four-dose treatment program. J Clin Oncol. 1998;16(8):2825-2833.

13. Nguyen DT, Amess JA, Doughty H, Hendry L, Diamond LW. IDECC2B8 anti-CD20 (rituximab) immunotherapy in patients with lowgrade non-Hodgkin's lymphoma and lymphoproliferative disorders: evaluation of response on 48 patients. Eur J Haematol. 1999;62(2): 76-82.

14. Winkler U, Jensen M, Manzke O, Schulz H, Diehl V, Engert A. Cytokine-release syndrome in patients with B-cell chronic lymphocytic leukemia and high lymphocyte counts after treatment with an anti-CD20 monoclonal antibody (rituximab, IDEC-C2B8). Blood. 1999;94(7):2217-2224.

15. Ladetto M, Bergui L, Ricca I, Campana S, Pileri A, Tarella C. Rituximab anti-CD20 monoclonal antibody induces marked but transient reductions of peripheral blood lymphocytes in chronic lymphocytic leukaemia patients. Med Oncol. 2000;17(3):203-210.

16. Huhn D, von Schilling C, Wilhelm M, et al. Rituximab therapy of patients with B-cell chronic lymphocytic leukemia. Blood. 2001; 98(5):1326-1331.

17. Itala M, Geisler CH, Kimby E, et al. Standard-dose anti-CD20 antibody rituximab has efficacy in chronic lymphocytic leukaemia: results from a Nordic multicentre study. Eur J Haematol. 2002;69(3): 129-134.

18. O'Brien SM, Kantarjian H, Thomas DA, et al. Rituximab dose-escalation trial in chronic lymphocytic leukemia. J Clin Oncol. 2001;19(8): 2165-2170.

19. Byrd JC, Murphy T, Howard RS, et al. Rituximab using a thrice weekly dosing schedule in B-cell chronic lymphocytic leukemia and small lymphocytic lymphoma demonstrates clinical activity and acceptable toxicity. J Clin Oncol. 2001;19(8):2153-2164.

20. Hainsworth JD, Litchy S, Barton JH, et al. Single-agent rituximab as first-line and maintenance treatment for patients with chronic lymphocytic leukemia or small lymphocytic lymphoma: a phase II trial of the Minnie Pearl Cancer Research Network. J Clin Oncol. 2003; 21(9):1746-1751.

21. Thomas DA, O'Brien S, Giles FJ, et al. Single agent retuxan in early stage chronic lymphocytic leukemia (CLL). ASH Annual Meeting Abstracts. 2001;98:Abstract 364a.

22. Byrd JC, Peterson BL, Morrison VA, et al. Randomized phase 2 study of fludarabine with concurrent versus sequential treatment with rituximab in symptomatic, untreated patients with B-cell chronic lymphocytic leukemia: results from Cancer and Leukemia Group B 9712 (CALGB 9712). Blood. 2003;101(1):6-14.

23. Woyach JA, Ruppert AS, Heerema NA, et al. Treatment with fludarabine and rituximab produces extended overall survival (OS) and progression-free survival (PFS) in chronic lymphocytic leukemia (CLL) without increased risk of second malignancy: long-term follow up of CALGB Study 9712. Blood (ASH Annual Meeting Abstracts). 2009;114(22):Abstract 539.

24. Schulz H, Klein SK, Rehwald U, et al. Phase 2 study of a combined immunochemotherapy using rituximab and fludarabine in patients with chronic lymphocytic leukemia. Blood. 2002;100(9): 3115-3120.

25. Byrd JC, Rai K, Peterson BL, et al. Addition of rituximab to fludarabine may prolong progression-free survival and overall survival in patients with previously untreated chronic lymphocytic leukemia: an updated retrospective comparative analysis of CALGB 9712 and CALGB 9011. Blood. 2005;105(1):49-53. 
26. Wierda W, O'Brien S, Wen S, et al. Chemoimmunotherapy with fludarabine, cyclophosphamide, and rituximab for relapsed and refractory chronic lymphocytic leukemia. J Clin Oncol. 2005; 23(18):4070-4078.

27. Tam CS, O'Brien S, Wierda W, et al. Long-term results of the fludarabine, cyclophosphamide, and rituximab regimen as initial therapy of chronic lymphocytic leukemia. Blood. 2008;112(4): 975-980.

28. Keating MJ, O’Brien S, Albitar M, et al. Early results of a chemoimmunotherapy regimen of fludarabine, cyclophosphamide, and rituximab as initial therapy for chronic lymphocytic leukemia. J Clin Oncol. 2005;23(18):4079-4088.

29. Lamanna N, Kalaycio M, Maslak P, et al. Pentostatin, cyclophosphamide, and rituximab is an active, well-tolerated regimen for patients with previously treated chronic lymphocytic leukemia. J Clin Oncol. 2006;24(10):1575-1581.

30. Kay NE, Geyer SM, Call TG, et al. Combination chemoimmunotherapy with pentostatin, cyclophosphamide, and rituximab shows significant clinical activity with low accompanying toxicity in previously untreated B chronic lymphocytic leukemia. Blood. 2007 109(2):405-411.

31. Hallek M, Fingerle-Rowson G, Fink A-M, et al. Immunochemotherapy with fludarabine (F), cyclophosphamide (C), and rituximab (R) (FCR) versus fludarabine and cyclophosphamide (FC) improves response rates and progression-free survival (PFS) of previously untreated patients (pts) with advanced chronic lymphocytic leukemia (CLL). Blood (ASH Annual Meeting Abstracts). 2008;112(11):Abstract 325.

32. Robak T, Moiseev SI, Dmoszynska A, et al. Rituximab, fludarabine, and cyclophosphamide (R-FC) prolongs progression free survival in relapsed or refractory chronic lymphocytic leukemia (CLL) compared with FC alone: final results from the international randomized phase III REACH trial. Blood (ASH Annual Meeting Abstracts). 2008;112(11): Abstract lba-1.

33. Hallek M, Fingerle-Rowson G, Fink A-M, et al. First-line treatment with fludarabine (F), cyclophosphamide (C), and rituximab (R) (FCR) improves overall survival (OS) in previously untreated patients (pts) with advanced chronic lymphocytic leukemia (CLL): results of a randomized phase III trial on behalf of an international group of investigators and the German CLL Study Group. Blood (ASH Annual Meeting Abstracts). 2009;114(22):Abstract 535.

34. Wierda WG, O’Brien S, Faderl S, et al. Combined cyclophosphamide, fludarabine, alemtuzumab, and rituximab (CFAR), an active regimen for heavily treated patients with CLL. Blood (ASH Annual Meeting Abstracts). 2006;108(11):Abstract 31.

35. Wierda WG, O’Brien S, Ferrajoli A, et al. Combined cyclophosphamide, fludarabine, alemtuzumab, and rituximab (CFAR), an active frontline regimen for high-risk patients with CLL. Blood (ASH Annual Meeting Abstracts). 2007;110(11):Abstract 628.

36. Parikh SA, Keating M, O'Brien S, et al. Frontline combined chemoimmunotherapy with fludarabine, cyclophosphamide, alemtuzumab and rituximab (CFAR) in high-risk chronic lymphocytic leukemia. Blood (ASH Annual Meeting Abstracts). 2009;114(22):Abstract 208.

37. Fischer K, Stilgenbauer S, Schweighofer CD, et al. Bendamustine in combination with rituximab (BR) for patients with relapsed chronic lymphocytic leukemia (CLL): A multicentre phase II trial of the German CLL Study Group (GCLLSG). Blood (ASH Annual Meeting Abstracts). 2008;112(11):Abstract 330.

38. Fischer K, Cramer P, Stilgenbauer S, et al. Bendamustine combined with rituximab (BR) in first-line therapy of advanced CLL: a multicenter phase II trial of the German CLL Study Group (GCLLSG). Blood (ASH Annual Meeting Abstracts). 2009;114(22):Abstract 205.

39. Keating MJ, Flinn I, Jain V, et al. Therapeutic role of alemtuzumab (Campath-1H) in patients who have failed fludarabine: results of a large international study. Blood. 2002;99(10):3554-3561.

40. Hillmen P, Skotnicki AB, Robak T, et al. Alemtuzumab compared with chlorambucil as first-line therapy for chronic lymphocytic leukemia. J Clin Oncol. 2007;25(35):5616-5623.
41. Faderl S, Thomas DA, O'Brien S, et al. Experience with alemtuzumab plus rituximab in patients with relapsed and refractory lymphoid malignancies. Blood. 2003;101(9):3413-3415.

42. Zent CS, Call TG, Shanafelt TD, et al. Early treatment of high-risk chronic lymphocytic leukemia with alemtuzumab and rituximab. Cancer. 2008;113(8):2110-2118.

43. Chanan-Khan A, Miller KC, Musial L, et al. Clinical efficacy of lenalidomide in patients with relapsed or refractory chronic lymphocytic leukemia: results of a phase II study. J Clin Oncol. 2006; 24(34):5343-5349.

44. Ferrajoli A, Lee BN, Schlette EJ, et al. Lenalidomide induces complete and partial remissions in patients with relapsed and refractory chronic lymphocytic leukemia. Blood. 2008;111(11):5291-5297.

45. Chen C, Paul H, Xu W, et al. A Phase II Study of lenalidomide in previously untreated, symptomatic chronic lymphocytic leukemia (CLL). Blood (ASH Annual Meeting Abstracts). 2008;112(11): Abstract 44.

46. Ferrajoli A, Badoux XC, O'Brien S, et al. Combination therapy with lenalidomide and rituximab in patients with relapsed chronic lymphocytic leukemia (CLL). Blood (ASH Annual Meeting Abstracts). 2009; 114(22):Abstract 206.

47. Thornton PD, Matutes E, Bosanquet AG, et al. High dose methylprednisolone can induce remissions in CLL patients with p53 abnormalities. Ann Hematol. 2003;82(12):759-765.

48. Bowen DA, Call TG, Jenkins GD, et al. Methylprednisolone-rituximab is an effective salvage therapy for patients with relapsed chronic lymphocytic leukemia including those with unfavorable cytogenetic features. Leuk Lymphoma. 2007;48(12):2412-2417.

49. James AF, Castro JE, Sandoval-Sus JD, et al. Rituximab and high-dose methylprednisolone for the initial treatment of chronic lymphocytic leukemia is associated with promising clinical activity and minimal hematologic toxicity. Blood (ASH Annual Meeting Abstracts). 2008;112(11):Abstract 47.

50. Venugopal P, Sivaraman S, Huang XK, Nayini J, Gregory SA Preisler HD. Effects of cytokines on CD20 antigen expression on tumor cells from patients with chronic lymphocytic leukemia. Leuk Res. 2000; 24(5):411-415.

51. Ferrajoli A. Incorporating the use of GM-CSF in the treatment of chronic lymphocytic leukemia. Leuk Lymphoma. 2009;50(3):514-516.

52. Carson KR, Evens AM, Richey EA, et al. Progressive multifocal leukoencephalopathy after rituximab therapy in HIV-negative patients: a report of 57 cases from the Research on Adverse Drug Events and Reports project. Blood. 2009;113(20):4834-4840.

53. Niscola P, Del Principe MI, Maurillo L, et al. Fulminant B hepatitis in a surface antigen-negative patient with B-cell chronic lymphocytic leukaemia after rituximab therapy. Leukemia. 2005;19(10):1840-1841.

54. Yeo W, Chan TC, Leung NW, et al. Hepatitis B virus reactivation in lymphoma patients with prior resolved hepatitis B undergoing anticancer therapy with or without rituximab. J Clin Oncol. 2009;27(4):605-611.

55. Shanafelt TD, Lin T, Geyer SM, et al. Pentostatin, cyclophosphamide, and rituximab regimen in older patients with chronic lymphocytic leukemia. Cancer. 2007;109(11):2291-2298.

56. Del Poeta G, Del Principe MI, Buccisano F, et al. Consolidation and maintenance immunotherapy with rituximab improve clinical outcome in patients with B-cell chronic lymphocytic leukemia. Cancer. 2008;112(1):119-128

57. Foon KA, Boyiadzis M, Land SR, et al. Chemoimmunotherapy with low-dose fludarabine and cyclophosphamide and high dose rituximab in previously untreated patients with chronic lymphocytic leukemia. J Clin Oncol. 2009;27(4):498-503.

58. Nabhan C, Patton D, Gordon LI, et al. A pilot trial of rituximab and alemtuzumab combination therapy in patients with relapsed and/or refractory chronic lymphocytic leukemia (CLL). Leuk Lymphoma. 2004;45(11):2269-2273.

59. Frankfurt O, Hamilton E, Duffey S, et al. Alemtuzumab and rituximab Combination Therapy for Patients with Untreated CLL - a Phase II Trial. Blood (ASH Annual Meeting Abstracts). 2008;112(11):Abstract 2098. 
60. Dungarwalla M, Evans SO, Riley U, Catovsky D, Dearden CE, Matutes E. High dose methylprednisolone and rituximab is an effective therapy in advanced refractory chronic lymphocytic leukemia resistant to fludarabine therapy. Haematologica. 2008;93(3):475-476.
61. Castro JE, Sandoval-Sus JD, Bole J, Rassenti L, Kipps TJ. Rituximab in combination with high-dose methylprednisolone for the treatment of fludarabine refractory high-risk chronic lymphocytic leukemia. Leukemia. 2008;22(11):2048-2053.

\section{Publish your work in this journal}

The Journal of Blood Medicine is an international, peer-reviewed, open access, online journal publishing laboratory, experimental and clinical aspects of all topics pertaining to blood based medicine including but not limited to: Transfusion Medicine; Blood collection, Donor issues, Transmittable diseases, and Blood banking logistics; Immunohematology; Artificial and alternative

\section{Dovepress}

blood based therapeutics; Hematology; Biotechnology/nanotechnology of blood related medicine; Legal aspects of blood medicine; Historical perspectives. The manuscript management system is completely online and includes a very quick and fair peer-review system. Visit http://www.dovepress.com/ testimonials.php to read real quotes from published authors.

Submit your manuscript here: http://www.dovepress.com/Journal-of-blood-medicine-journal 